\title{
Metabolic syndrome and Cancer: Do they share common molecular pathways?
}

\author{
Veniou E., I. Sofatzis, I. Kalantzis, M. Karakosta, \\ M. Logothetis, E. Lianos, N.Ziras* \\ Medical Oncology, \\ Metaxa Cancer Hospital of Piraeus, \\ Departments of Medical Oncology and Endocrinology \\ Botassi 51, 18537 Piraeus, Greece
}

Received 21 June 2016; Accepted 25 August 2016

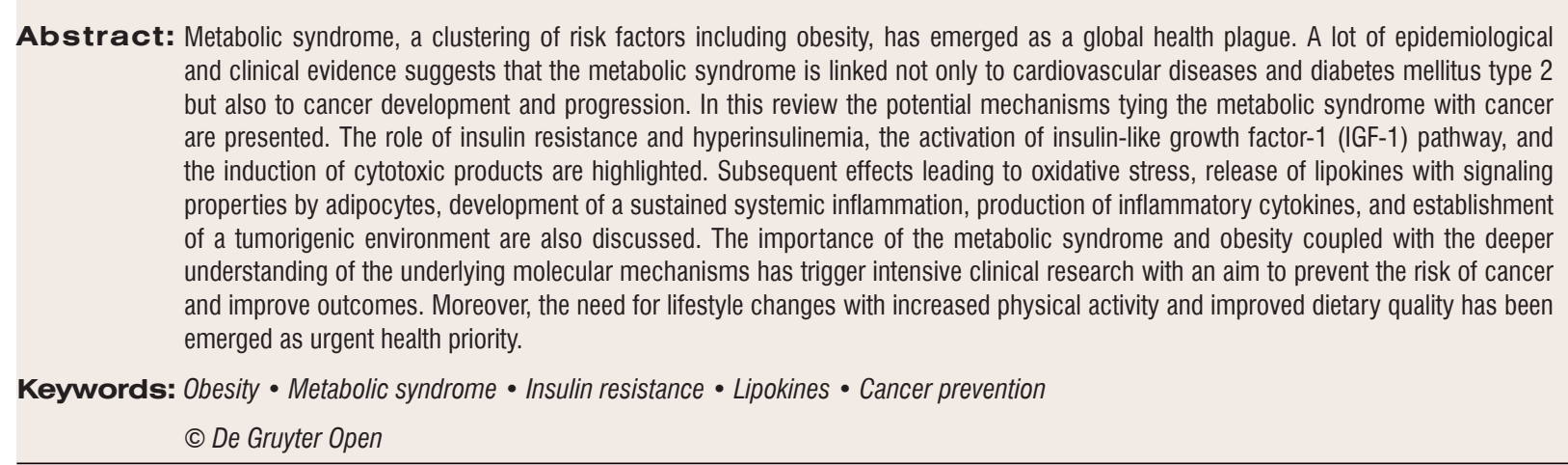

\section{Introduction}

Metabolic syndrome has been recognised as a continuously growing global health problem and comprises a number of risk factors for developing cardiovascular diseases and diabetes mellitus type 2. These factors include obesity, mainly abdominal, dysglycemia, arterial hypertension, high triglycerides levels and low HDL cholesterol levels [1].

Moreover, there is evidence that the metabolic syndrome is a major causing factor for developing certain types of cancer and that it negatively affects the overall cancer morbidity. There are 1.1 billion overweight people worldwide with a body mass index (BMI) between 25 and $30 \mathrm{~kg} / \mathrm{m}^{2}$ and 312 million obese people with a BMl>30 kg/m² [2].

It has been estimated that in 2012 , approximately $4 \%$ of new cancer cases worldwide - 345,000 women and 136,000 men - were found to have a high BMI. It has also been determined that if the BMI of the population had remained at the 1982 levels, that is those at 30 years ago, a quarter of new cancer cases associated with high BMI would have been prevented [3].

A population survey in the United Kingdom showed that an increase of BMI by $1 \mathrm{~kg} / \mathrm{m}^{2}$ leads to the development of 3,790 additional new cancer cases associated with BMI per year [4].

\section{Epidemiological data}

Plenty of epidemiological data derived from case-control and population cohort studies have associated the metabolic syndrome with the risk of developing various cancer types, including those of colon, breast (postmenopausal), endometrium, liver, stomach, pancreas and prostate [5-7].

However, in order to accurately interpret the findings of the epidemiological studies, limitations linked to the nature of these trials and possible co-existence of confounding or discriminatory factors should be taken 
Table 1. Definitions of the Metabolic Syndrome

\begin{tabular}{|c|c|c|c|}
\hline Risk Factors & $\begin{array}{l}\text { National Cholesterol } \\
\text { Education Program's } \\
\text { Adult Treatment Panel } \\
\text { III (ATP III) (8) } \\
\geq 3 \text { of } 5 \text { criteria necessary }\end{array}$ & $\begin{array}{l}\text { WHO } 1999^{(9)} \\
\text { Impaired glucose regulation or } \\
\text { hyperinsulinemia and } \\
\geq 2 \text { of criteria necessary }\end{array}$ & $\begin{array}{l}\text { European Group on Insulin } \\
\text { Resistance (EGIR) (10) } \\
\text { Hyperinsulinemia and } \\
\geq 2 \text { of criteria necessary }\end{array}$ \\
\hline $\begin{array}{l}\text { Abdominal } \\
\text { Obesity }\end{array}$ & $\begin{array}{l}\text { Men: waist circumference } \\
\geq 40 \text { inches }(102 \mathrm{~cm}) \\
\text { Women: waist circumference } \\
\geq 35 \text { inches }(89 \mathrm{~cm})\end{array}$ & Waist-to-hip ratio $>0.85$ or $\mathrm{BMI}>30 \mathrm{~kg} / \mathrm{m} 2$ & Waist circumference $>80 \mathrm{~cm}$ \\
\hline Dysglycemia & $\begin{array}{l}110-126 \mathrm{mg} / \mathrm{dl} \\
(6.1-7.0 \mathrm{mmol} / \mathrm{L})\end{array}$ & $\begin{array}{l}\text { Plasma glucose: fasting } \geq 6.1 \mathrm{mmol} / \mathrm{L} \\
\text { or 2-hour postglucose load } \geq 7.8 \mathrm{mmol} / \mathrm{L} \\
\text { or Capillary whole blood glucose: } \\
\text { fasting } \geq 5.6 \mathrm{mmol} / \mathrm{L} \text { or } 2 \text {-hour } \\
\text { postglucose load } \geq 7.8 \mathrm{mmol} / \mathrm{L}\end{array}$ & $\begin{array}{l}\text { Fasting plasma } \geq 6.1 \mathrm{mmol} / \mathrm{L} \text { or } \\
\text { capillary whole blood } \geq 5.6 \mathrm{mmol} / \mathrm{L}\end{array}$ \\
\hline Hyperinsulinemia & Not included & $\begin{array}{l}\text { Fasting serum insulin } \geq \text { third quartile for } \\
\text { control group }\end{array}$ & $\begin{array}{l}\text { Fasting serum insulin } \geq \text { third quartile } \\
\text { for nondiabetic control group }\end{array}$ \\
\hline Hypertension & $\geq 130 / \geq 80 \mathrm{mmHg}$ & $\geq 140 / 90 \mathrm{mmHg}$ & $\begin{array}{l}\text { Systolic blood pressure } \geq 140 \mathrm{mmHg} \\
\text { and/or diastolic blood pressure } \\
\geq 90 \mathrm{mmHg} \text { and/or treatment for } \\
\text { hypertension }\end{array}$ \\
\hline Triglycerides & $\geq 150 \mathrm{mg} / \mathrm{dl}(1.7 \mathrm{mmol} / \mathrm{L})$ & Fasting serum triglyceride $\geq 1.7 \mathrm{mmol} / \mathrm{L}$ & $\begin{array}{l}\text { Fasting serum triglyceride } \\
>2.0 \mathrm{mmol} / \mathrm{L} \text { and/or } \\
\mathrm{HDLC}<1.0 \mathrm{mmol} / \mathrm{L} \text { and/or } \\
\text { treatment for dyslipidemia }\end{array}$ \\
\hline HDLC & $\begin{array}{l}\text { Men: } \leq 40 \mathrm{mg} / \mathrm{dl}(1.04 \mathrm{mmol} / \mathrm{L}) \\
\text { Women: } \leq 50 \mathrm{mg} / \mathrm{dl}(1.3 \mathrm{mmol} / \mathrm{L})\end{array}$ & Not included & Included with triglycerides \\
\hline
\end{tabular}

into account. Furthermore, as indicated in Table 1, a universally accepted definition of the metabolic syndrome is missing and different criteria have been adopted by several groups [8-10].

In the meta-analysis of Esposito et al. [11], 2,628 publications were reviewed and 43 cohort studies were selected under strict criteria for analysis, involving 38,940 cancer patients who met at least three criteria of the metabolic syndrome and had a median follow-up time between 3 and 12 years. Overall, the relative risks were low ranging from 1.1 to 1.6 , and for certain types of cancer, they varied between genders and nationalities (Figure 1). In men, the metabolic syndrome was strongly associated with colorectal cancer, while hepatoma and urinary bladder cancer showed a weaker correlation. On the other hand, in women, the respective correlation to colon and pancreas cancers was moderate, while for post-menopausal breast cancer and endometrial cancer, a weaker correlation was observed. Finally, the estimated risk for cancer mortality was $1.61(p<0.0001)$.

\section{Mechanisms linking metabolic syndrome to cancer}

In recent years, there is an intense scientific research to decipher the mechanism linking the metabolic syndrome to the development and progression of

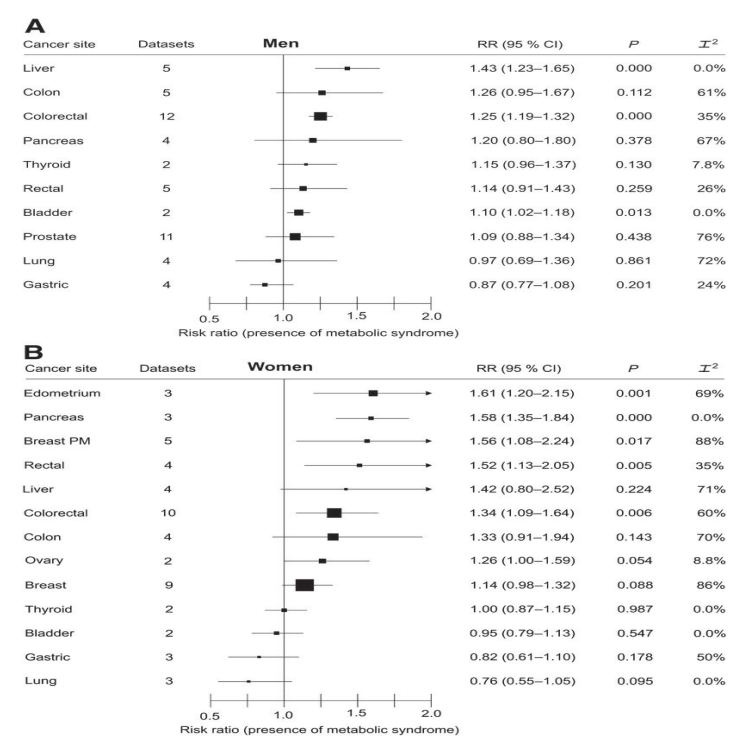

Figure 1. Correlation between metabolic syndrome and cancer: risk estimates by cancer sites in men (A) and women (B) (11).

various neoplastic diseases. Although the mechanisms are not fully understood, the importance of insulin resistance and hyperinsulinemia, as well as the role of insulin-like growth factor-1 (IGF-1) pathway, hyperglycemia, and production of toxic products such as 
advanced glycation dnd-products (AGEs) and reactive oxygen species (ROS) have emerged. These contribute to the occurrence of oxidative stress and cellular destruction, secretion of cytokines from adipocytes and other proteins with signalling properties, generally called adipokines, and chronic systemic inflammation, which accompanies obesity and leads to the production of inflammatory cytokines and the generation of tumorigenic environment [12-16].

\section{Insulin resistance / hyperinsulinemia / IGF-1 pathway stimulation}

Metabolic syndrome is characterised by insulin resistance that implies the establishment of hyperinsulinemia. The existing literature advocates the association of dysglycemia and hyperinsulinemia with the risk of colon cancer. Moreover, postprandial concentrations of C-peptide, a measure of insulin secretion, are a stronger predictor of colorectal cancer when metabolic syndrome is also taken into account.

Insulin has two cell receptors, IR-A and IR-B. The structures of IR/IGF-1R are shown in Figure 2. IR and IGF-1R have two extracellular $\alpha$-subunits and two transmembrane $\beta$-subunits were joined to each other by disulphide bonds. Insulin binds with high affinity to IR-A or IR-B but has low affinity for IGF-1R and does not bind to the hybrid receptors. IGF-1 binds to the IGF$1 \mathrm{R}$ and to the hybrid receptor IGF-1R/IR-A or IGF-1R/ IR-B, while IGF-2 binds to IR-A, IGF-1R or to IGF-1R/ IR-A hybrid receptor. Ligand binding to IR-A or IGF-1R mediates the mitogenic signalling pathway, while ligand binding to IR-B activates metabolic effects. Binding to the hybrid receptors, leading to mitogenic or metabolic activity, is determined by the IR isoform that formed the hybrid receptors. The IR-B receptor is mainly expressed in the liver, muscle and adipocytes, while IR-A is expressed in tumour cells and this may explain why hyperinsoulinemia can promote cancer development in diabetic and obese patients.

Insulin may also cause the proliferation of cancer cells indirectly through an indirect IGF-1 stimulation. Insulin stimulates the production of IGF-1 by upregulating the $\mathrm{GH}$ receptors in the liver. Activation of IGF-1R induces cell proliferation through RAS/MAPK signalling pathway and has anti-apoptotic effect via the PI3K/AKT pathway (Figure 3).

It is known that mTOR pathway is critical for the regulation of cell proliferation and protein synthesis. AMPactivated protein kinase (AMPK) acts as a sensor of the energy status of the organism. In case of energy depletion, activation of AMPK occurs, involving the suppression of

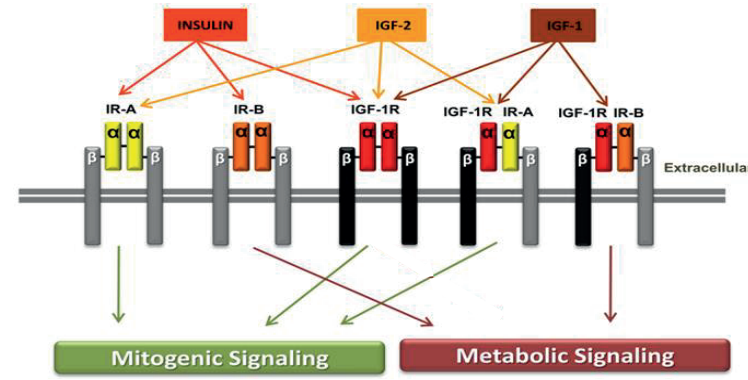

Figure 2. The insulin receptor (IR) with its two subtypes IR-A and IR-B, the IGF-IR and the hybrid receptors IGF-1R/IR-A and IGF-1R/IR-B.

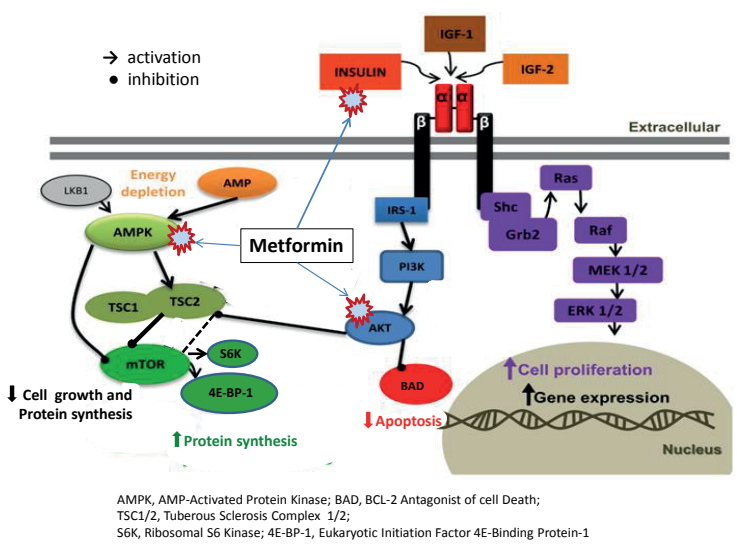

Figure 3. The signalling pathway of insulin-like growth factor-1 receptor (IGF-1R). Modified from Braun et al. (13).

mTOR with consequent suppression of cell growth and protein production. The suppressive activity of AMPK is affected either by direct suppression of mTOR or indirectly through activation of TCS1/TCS2 tumour suppressor complex, which also suppresses mTOR. In regulating protein synthesis, activated AKT is also involved, by removing the inhibitive effect of TCS1 / TCS2 complex on mTOR, leading to enhanced protein synthesis through activation of $\mathrm{S} 6$ kinase and 4E-BP-1 factor (Figure 3).

Metformin activates AMPK and suppresses AKT and insulin levels. Both mechanisms lead to inhibition of cell growth and therefore might explain why metformin can be associated with a reduced risk of cancer development and a better response to treatment, as mTOR activation is also related to subsequent resistance to anticancer agents such as trastuzumab and tamoxifen.

Hyperinsulinemia also increases the availability of IGF-1, by reducing the secretion of proteins that bind the IGF (IGFBP) from the liver, thus releasing more IGF-1 free to bind to its receptors on target cells.

Epidemiological studies have highlighted the association of increased IGF-1 levels and reduced IGFBP-3 levels 
with premenopausal breast cancer, as well as colon and prostate cancers. Also, IGF-1 pathway stimulates angiogenesis by increasing the production of vascular endothelial growth factor (VEGF). Furthermore, hyperinsulinemia and the excess of free IGF-1 suppress the synthesis of sex hormone binding globulins (SHBGs), by increasing the availability of estrogens and androgens and thereby promoting the development of hormone dependent cancers, such as those of the breast, endometrium and prostate.

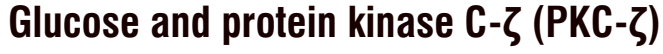 dysregulation / AGEs}

The metabolic syndrome is characterised by increased glucose levels in the circulation. It is known that increased glucose uptake by tumours is associated with more aggressive behaviour and poorer prognosis. Prospective studies are already investigating the possible suppressive effect of energy restriction on cancer development and progression.

Oral antidiabetics may suppress carcinogenesis through a theoretical mechanism of calorie restriction, thus reducing hyperinsulinemia, hyperglycaemia and oxidative stress. Such an effect may be mediated by restoring the function of $\mathrm{PKC}-\zeta$ in skeletal muscles. $\mathrm{PKC}-\zeta$ kinase is engaged in glucose uptake, apoptosis and VEGF signalling pathway, thus playing an important role in the progression of cancer. The metabolic syndrome is characterised by decreased PKC- $\zeta$ effect on the muscles, but not on the liver. Failure of the muscles to uptake glucose leads to hyperinsulinemia, which enhances the activity of liver $\mathrm{PKC}-\zeta$ by increasing the production of lipids, causing hypertriglyceridemia and lowering the levels of HDL lipids. Antidiabetic drugs, such as metformin and rosiglitazone, increase the AMPK effect on skeletal muscles, which restore the effect of $\mathrm{PKC}-\zeta$. Consequently, the diminished hyperinsulinemia may limit its effects on cancer cells.

Hyperglycaemia may have an additional mechanism of action through AGEs, which are produced by nonenzymatic glycation of proteins with reducing sugars. The oxidation of glycosylated proteins or interaction of AGEs with cellular receptors ultimately leads to the production of superoxide radicals, namely ROS, which contribute to oxidative stress and cell damage.

Plenty of dietary agents with antioxidant effects, such as olive oil, soy, omega- 3 fatty acids, fresh fruits and vegetables, are associated with a protective effect against breast and colon cancers. However, it is not clear if the antioxidant effect itself is sufficient to justify their anti-cancer properties.
AGEs have a receptor (RAGE), belonging to the superfamily of immunoglobulins and can bind multiple ligands, including AGEs as well as amphoterin, an important protein involved in the regulation of inflammation, oncogenesis and cellular differentiation and migration. The receptor is expressed in many cancers such as colon, pancreatic and prostate cancer, but not in lung and esophageal cancer. Binding of AGEs causes genotoxic effect via an oxidative mechanism while the binding of amphoterin increases cancer cell migration and invasion. Thus, overexpression and upregulation of RAGE may be a mechanism by which the metabolic syndrome aggravates cancer prognosis and might be a therapeutic target.

\section{Lipokines}

Adipose tissue does not only provide energy storage by fat accumulation. It is a complex endocrine organ, which secrete more than 50 proteins, the so-called lipokines, which intervene in the regulation of glucose and insulin, energy balance, lipid metabolism, chronic inflammation, angiogenesis, cell proliferation and apoptosis. All these activities may associate the metabolic syndrome with cancer.

\section{Aromatase}

The enzyme complex of cytochrome P450, known as aromatase, found in fat cells and adipocyte stromal tissue, is responsible for converting androgens to estradiol. Obesity predisposes to increased estrogen production and is associated with a twofold increase in risk of postmenopausal breast cancer and a two- to fivefold increase in risk of endometrial cancer.

There is also increased production of TNF- $\alpha$ and IL-6 cytokines by adipocytes in obese women, which stimulates aromatase activity and production of estradiol, increasing thus the risk of hormone-dependent breast and endometrial cancers.

\section{Leptin}

Leptin is an adipocyte-specific hormone regulating satiety, body weight and energy intake. Its levels in circulation are directly related to fat accumulation. However, obese people develop resistance to leptin and become hyperleptinemic and susceptible to insulin resistance. Increased leptin levels stimulate cell proliferation via MAPK pathway, as well as angiogenesis, thereby increasing the risk of developing prostate, breast, colon and endometrial cancers.

\section{Adiponectin}

This hormone, in contrast to other adipocyte-secreted hormones, is reduced in obese and diabetic patients. 
Adiponectin improves insulin resistance, reduces the concentrations of plasma free fatty acid and has antiinflammatory and anti-angiogenic properties. In addition, there is an inverse correlation between its levels and stomach, breast and endometrium cancers, thus being considered as preventive to cancer development. In contrast, certain polymorphisms of adiponectin genes and their receptors have been associated with increased cancer risk.

\section{Angiogenesis}

Adipocytes, especially the omental ones, secrete VEGF and its levels are increased in patients with metabolic syndrome. The secretion of VEGF from various tissues including adipose is induced by hypoxia and other factors, such as insulin, IGF-1, leptin, estrogen and TNF- $\alpha$, all increased in obesity. However, the specific role of the adipocyte-derived VEGF in cancer progression still remains unclear. Apart from VEGF, angiogenesis can be stimulated via insulin and its receptor, reported as overexpressed in peritumoral vessels.

\section{Inflammation / Immunity}

Adipocytes secrete various cytokines, including TNF- $\alpha$, IL-6, IL-8, IL-10 and MIP-1. The metabolic syndrome is characterised by a chronic low-level inflammation, with high IL-6 levels and low anti-inflammatory IL-10 levels. TNF- $\alpha$ and IL- 6 cytokines are constantly increased in the adipose tissue and serum of obese patients and promote insulin resistance and increase in circulating triglycerides. Free fatty acids stimulate multiple inflammatory signalling pathways, finally leading to the activation of NF-kB transcription factor that plays an important role in the immune response and inflammation of the adipose tissue.

Dead adipocytes release free fatty acids, which through the mediation of toll-like receptor-4 (TLR-4) and the activation of NF-kB lead to the formation of ROS and the production of pro-inflammatory cytokines from stimulated macrophages. These cytokines generate further lipolysis and release of free fatty acids, thus establishing a feedback mechanism of sustained inflammation.

Inflammation has been associated with various cancers such as stomach, pancreas, esophagus, liver and urinary bladder. High IL-6 levels are also prognostic in patients with colorectal cancer. Overall, cytokine secretion by adipose tissue promotes the cancerous process through insulin resistance, inflammation and ROS production.

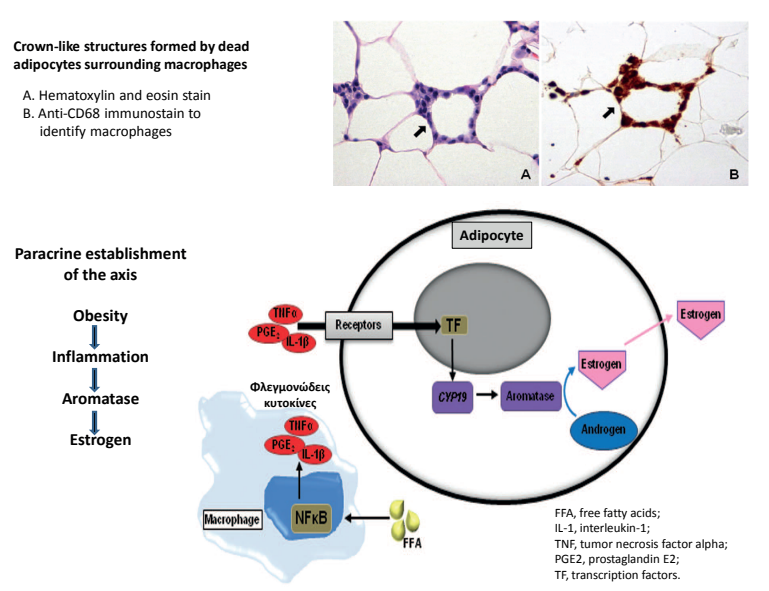

Figure 4. Paracrine establishment of the axis obesity-inflammationaromatase stimulation-estrogen secretion induced by activated macrophages in the breast tissue of obese women being at risk for breast cancer. Modified from lyengar et al. (17)

Intratumoral immune regulation plays a key role in the immunological control of tumours. In colon cancer, increased expression of amphoterin is associated with decrease in macrophages infiltrating the tumour.

Adipocytes release several pro-inflammatory cytokines contributing to the accumulation and activation of immune cells such as macrophages. Dead adipocytes are surrounded by infiltrating macrophages to form characteristic crown-like structures (Figure 4). These structures, which are observed in the fat of the breasts of obese women, are related to NF-kB activation and increased secretion of pro-inflammatory cytokines, which are inducers of increased aromatase activity and estrogen biosynthesis promoting the development of hormone-dependent breast cancer [17].

\section{Hypertriglyceridemia and ROS production}

Apart from glucose, ROS may be formed from triglycerides, thus promoting carcinogenesis in a synergistic or additive manner. Triglyceride accumulation in the cytoplasm of hepatic and muscle cells enhances ROS production by mitochondria.

ROS can also react with lipids. Fatty acids are susceptible to oxidation, forming active peroxidative products, which are decomposed into reactive aldehydes. These, in turn, can cause mutation of p53 as in hepatoma and upregulation of COX-2, which is associated with breast, colon and prostate cancers.

Thus, hyperlipidemia and obesity contribute to the development of ROS and oxidative stress accompanying the metabolic syndrome and may be involved in cancer. 
Regulation of peroxisome proliferator-activated receptor (PPAR)

There are three nuclear hormone receptors (PPAR $\alpha$, $\beta / \delta$, and $\gamma$ ) that interact with multiple cellular pathways. PPAR-y receptor is overexpressed in the muscles of obese and diabetic patients, induced by insulin, and regulates the metabolism of glucose and the storage of fatty acids. PPAR-y activation due to use of thiazolidinediones, improves insulin sensitivity and provides anti-inflammatory and anti-proliferative effects. In a cohort study of diabetic patients, the use rosiglitazone or pioglitazone, which are selective PPAR-y ligands, was associated with a significant decrease in lung cancer risk but the risk reduction for colon and prostate cancer did not reach statistical significance [18]. In another cohort study, long-term users of thiazolidinediones experienced an increased risk of bladder cancer [19].

PPAR- $\beta / \delta$ seems to mediate the EGFR-induced tumour growth.

Overall, despite the anti-tumour properties of PPAR agonists, the correlation of the endogenous overexpression of these receptors with the risk of cancer in patients with metabolic syndrome is still ambiguous.

\section{Hypertension and HDL concentration}

The mechanism that could associate hypertension and HDL concentration to carcinogenesis still remains unclear.

\section{Awareness of the scientific community on the "obesity and cancer" issue}

It has been estimated that more than $50 \%$ of the 1.6 million new cancer cases each year in the United States could have been prevented if there were regular preventive checks and lifestyle changes with regular exercise and healthy diet [20].

A deeper understanding of the molecular mechanisms of metabolic syndrome, together with affluent epidemiological data, further highlight its relationship with the development and progression of cancer. Obesity has emerged as a global health problem with health, economic and social consequences rivalling smoking.

Recognising the importance of the issue, current studies evaluate the effect of BMI on the outcome of cancer patients. In the CALGP 9741 trial, all 2,005 enrolled women had an early-stage node-positive breast cancer and received chemotherapy optimally dosed by actual body weight. On multivariate analysis, after a median follow-up of 11 years, BMI at diagnosis was a significant predictor of both recurrence-free and overall survival [21]. In the 20050181 study, the addition of panitumumab to FOLFIRI in second-line treatment of patients with metastatic colorectal cancer was assessed. In the posthoc analysis among patients with wild-type RAS tumours, the survival benefit of panitumumab was lost in the subgroup of patients with a BMI $\geq 30 \mathrm{mg} / \mathrm{m}^{2}$ [22].

\section{Position statement of the American Society of Clinical Oncology (ASCO) on obesity and cancer}

ASCO has recently defined the following priorities to deal with the issue of obesity and cancer [23].

\section{Education and awareness}

The aim is to provide the necessary knowledge to health professionals and awareness to general public and vulnerable population groups about the impact of energy balance on cancer prevention.

\section{Clinical guidelines and tools}

This action refers to the need of practical guidance and communication tools formulation, for example, for BMI calculation, practical guidelines to healthy nutrition and physical activity, in order to help oncology professionals to provide appropriate advice to patients regarding obesity treatment and energy balance maintenance.

\section{Health policy-making}

The aim is to formulate appropriate policies in order to deal with the social factors that favour obesity and unhealthy lifestyle. The advocacy of patients' right to easy access to health services for obesity prevention and treatment is also mandatory.

\section{Research promotion}

The aim is to implement research programmes to assess how behavioural and lifestyle changes after cancer diagnosis, namely weight loss, better diet and increased physical activity, could improve prognosis. Relevant studies, funded by the $\mathrm{NCl}$ and other organisations, are already underway (Table 2). Prospective studies are also in progress in specific population cohorts investigating the relationship between obesity and physical activity to the risk of cancer development. These projects require extensive funding and inter-disciplinary approach through the collaboration of all involved scientists, including physicians of various specialties, nutritionists, 
Table 2. Ongoing studies investigating the effects of obesity and physical activity on cancer development and patient outcomes.

\begin{tabular}{l|l}
\hline NCI-Funded Initiatives & \\
\hline \hline $\begin{array}{l}\text { Transdisciplinary Research on Energetics } \\
\text { and Cancer (TREC) }\end{array}$ & $\begin{array}{l}\text { The TREC initiative links four research centers and a coordination center to investigate how the } \\
\text { combined effects of obesity, poor diet, and low levels of physical activity increase cancer risk. The } \\
\text { Initiative helps scientists conduct research across multiple disciplines and trains new and established } \\
\text { researchers capable of carrying out this kind of integrated research. }\end{array}$ \\
\hline $\begin{array}{l}\text { Breast Cancer Surveillance Consortium } \\
\text { (BCSC) }\end{array}$ & $\begin{array}{l}\text { The BCSC is a research resource for studies designed to assess the delivery and quality of breast } \\
\text { cancer screening, and related patient outcomes. Through the BCSC, NCl is funding studies to } \\
\text { examine why there are lower rates of breast cancer screening among obese adults. }\end{array}$ \\
\hline $\begin{array}{l}\text { National Collaborative on Childhood } \\
\text { Obesity Research } \\
\text { (NCCOR) }\end{array}$ & $\begin{array}{l}\text { NCCOR brings together four of the nation's leading funders of childhood obesity research: the CDC, } \\
\text { NIH, Robert Wood Johnson Foundation, and the U.S. Department of Agriculture. NCI has been an } \\
\text { active and leading participant in NCCOR activities related to measurement, surveillance, and policy } \\
\text { evaluation. }\end{array}$ \\
\hline $\begin{array}{l}\text { Research and Policy } \\
\text { Resources }\end{array}$ & \\
\hline
\end{tabular}

=

National Health and Nutrition Examination Survey (NHANES)

Genes, Environment and Health Initiative

(GEI)
In collaboration with the National Center for Health Statistics, which is part of the CDC, $\mathrm{NCl}$ is supporting the use of activity monitors to collect objective physical activity, sleep, and strength data for NHANES

This trans- $\mathrm{NIH}$ includes an $\mathrm{NCl}$-led component that invests in new technology to measure environmental toxins, dietary intake, and physical activity and to determine an individual's biological response to those influences on the level of the genome, the proteome, and the metabolome.

Measures Registry
Catalogue of Surveillance Systems

In partnership with $\mathrm{NCCOR}, \mathrm{NCl}$ has developed these two online resources to help researchers and clinicians identify validated measures and datasets relevant to obesity and health behaviors and environmental factors.

Cancer Control PLANET

(Plan, Link, Act, Network With

Evidence-Based Tools)

The modules on Cancer Control PLANET include science-based information on interventions related to diet and physical activity that can help planners, program staff, and researchers design, implement, and evaluate science-based cancer control programs.

\section{Population Studies}

Prostate, Lung, Colorectal, and Ovarian Cancer Screening Trial Polyp Prevention Trial

Researchers are looking at groups of people within these studies to learn more about the influence of obesity and physical activity on all major cancer types, as well as some of the less common cancers.

NIH-AARP Diet and Health Study
Nurses' Health Study lowa Women's Health Study Health Professionals Follow-up Study Women's Health Initiative
This is a prospective cohort study of nutrition in relation to major cancers among over half a million American men and women. Results from this large cohort have already contributed to our understanding of the relationship between obesity and non-Hodgkin lymphoma, as well as prostate, endometrial, pancreatic, bladder, kidney, thyroid, and colorectal cancer

These large studies conducted by researchers around the country, with support from $\mathrm{NCl}$, have made

This joint intramural/extramural initiative combines more than 20 prospective cohort studies from around the world, which have enrolled more than two million participants collectively. The studies are gathering information on energy balance-related factors from each cohort. The large size of the study will allow researchers to get a better sense of how obesity-related factors relate to less common cancers, such as thyroid and gallbladder cancer.

Multiethnic Cohort Study

Southern Community Cohort Study

Black Women's Health Study

Adventist Health Study 2

California Teachers Study
In light of concerns about the potential for differential effects of obesity in diverse populations, $\mathrm{NCl}$ supports research that has the potential to examine obesity and cancer associations in non-white populations.

physiotherapists and psychologists. 
[1] Alberti KG, Eckel RH, Grundy SM, Zimmet PZ, Cleeman JI, Donato KA, Fruchart JC, James WP, Loria CM, Smith SC Jr. Harmonizing the metabolic syndrome: a joint interim statement of the International Diabetes Federation Task Force on Epidemiology and Prevention; National Heart, Lung, and Blood Institute; American Heart Association; World Heart Federation; International Atherosclerosis Society; and International Association for the Study of Obesity. Circulation 2009; 120:1640-1645.

[2] Haslam DW, James WP. Obesity. Lancet 2005; 366:1197-1209.

[3] Arnold M, Pandeya N, Byrnes G, Renehan AG, Stevens GA, Ezzati M, Ferlay J, Miranda JJ, Romieu I, Dikshit R, Forman D, Soerjomataram J. Global burden of cancer attributable to high bodymass index in 2012: a population-based study. Lancet Oncol 2015; 16:36-46.

[4] Bhaskaran K, Douglas I, Forbes H et al. Body-mass index and risk of 22 specific cancers: a populationbased cohort study of 5.24 million UK adults. Lancet 2014; 384(9945):755-765.

[5] Renehan AG, Tyson M, Egger M, Heller RF, Zawhlen M. Body-mass index and incidence of cancer: a systematic review and meta-analysis of prospective observational studies. Lancet 2008; 371:569-578.

[6] Nicolucci A. Epidemiological aspects of neoplasms in diabetes. Acta Diabetol 2010; 47:87-95.

[7] Jafri H, Alsheikh-Ali AA, Karas RH. Baseline and on-treatment high-density lipoprotein cholesterol and the risk of cancer in randomized controlled trials of lipid-altering therapy. J Am Coll Cardiol 2010; 55:2846-2854.

[8] Third report of the National Cholesterol Education Program (NCEP) expert panel on detection, evaluation, and treatment of high blood cholesterol in adults (Adult Treatment Panel III). Final report. Circulation. 2002; 106: 3143-3421.

[9] World Health Organization. Definition, diagnosis and classification of diabetes mellitus and its complications: report of a WHO Consultation. Part 1: diagnosis and classification of diabetes mellitus. Geneva, Switzerland: World Health Organization; 1999.

[10] Alberti KG, Zimmet P, Shaw J. IDF Epidemiology Task Force Consensus Group. The metabolic syndrome-a new worldwide definition. Lancet 2005; 366:1059-1062.
[11] Esposito K, Chiodini P, Colao A, Lenzi A, Giugliano D. Metabolic syndrome and risk of cancer. A systematic review and meta-analysis. Diabetes Care 2012; 35:2402-2411.

[12] Cowey S, Hardy RW. The metabolic syndrome: A high-risk state for cancer? Am J Pathol 2006; 169:1505-1522.

[13] Braun S, Bitton-Worms K, LeRoith D. The link between the metabolic syndrome and cancer. Int J Biol Sci 2011; 7:1003-1015.

[14] Fujihara S, Mori H, Kobara H, Nishiyama N, Kobayashi M, Oryu M, Masaki T. Metabolic syndrome, obesity, and gastrointestinal cancer. Gastroenterol Res Pract. 2012 (2012), Article ID 483623

[15] Extermann M. Metabolic syndrome and cancer: From bedside to bench and back. Interdiscipl Top Gerontol 2013; 38:49-60.

[16] Gallagher EJ, LeRoith D. Epidemiology and molecular mechanisms tying obesity, diabetes, and the metabolic syndrome with cancer. Diabetes Care 2013; 36(S2): S233-S239.

[17] lyengar NM, Hudis CA, Dannenberg AJ. Obesity and inflammation: new insights into breast cancer development and progression. ASCO Educational Book 2013: 46-51.

[18] Govindarajan R, Ratnasinghe L, Simmons DL, Siegel ER, Midathada MV, Kim L, Kim PJ, Owens RJ, Lang NP. Thiazolidinediones and the risk of lung, prostate, and colon cancer in patients with diabetes. J Clin Oncol 2007; 25: 1476-1481.

[19] Mamtani R, Haynes K, Bilker WB, Vaughn DJ, Strom BL, Glanz K, Lewis JD. Association between longer therapy with thiazolidinediones and risk of bladder cancer: a cohort study. J Natl Cancer Inst 104(18): 1411-1421.

[20] Colditz GA, Wolin KY, Gehlert S. Applying what we know to accelerate cancer prevention. Sci Transl Med 2012; 4(127): 127rv4.

[21] Ligibel JA, Cirrincione CT, Liu M, Citron M, Ingle JN, Gradishar W, Martino S, Sikov W, Michaelson $R$, Mardis E, Perou CM, Ellis M, Winer E, Hudis CA, Berry D, Barry WT. Body Mass Index, PAM50 Subtype, and Outcomes in Node-Positive Breast Cancer: CALGB 9741 (Alliance). J Natl Cancer Inst 2015; 107(9): djv179doi: 10.1093/jnci/djv179.

[22] Peeters $M$, Price T, Cervantes A, Sobrero A, Ducreux MP, André T, Lordick F, Punt C, Koukakis R, Terwey J, Van Cutsem E. Impact of baseline covariates and prior therapy on the efficacy of 
second-line panitumumab (PMAB) + FOLFIRI vs FOLFIRI treatment. Ann Oncol 2014; 25(Suppl 4): iv187-188 (548P).

[23] Ligibel JA, Alfano CM, Courneya KS, DemarkWahnefried W, Burger RA, Chlebowski RT, Fabian CJ, Gucalp A, Hershman DL, Hudson MM, Jones LW, Kakarala M, Ness KK, Merrill JK, Wollins DS, Hudis CA. American Society of Clinical Oncology Position Statement on Obesity and Cancer. J Clin Oncol 2014; 32: 3568-3574. 